\title{
Predicting the Ventilatory Support Necessity for Acute Exacerbation of Chronic Obstructive Pulmonary Disease Patients Using Rapid Shallow Breathing Index
}

\author{
Mohamed Megahed ${ }^{1, ~ *}$, Tamer Habib ${ }^{1}$, Eman Dwidar ${ }^{1}$, Islam Ahmed ${ }^{2}$ \\ ${ }^{1}$ Critical Care Department, Faculty of Medicine, Alexandria University, Alexandria, Egypt \\ ${ }^{2}$ Clinical Pharmacy Specialist, Faculty of Pharmacy, Alexandria University, Alexandria, Egypt
}

Email address:

dr.muhammed.megahed@gmail.com (M. Megahed)

*Corresponding author

\section{To cite this article:}

Mohamed Megahed, Tamer Habib, Eman Dwidar, Islam Ahmed. Predicting the Ventilatory Support Necessity for Acute Exacerbation of Chronic Obstructive Pulmonary Disease Patients Using Rapid Shallow Breathing Index. Journal of Anesthesiology.

Vol. 5, No. 3, 2017, pp. 24-28. doi: 10.11648/j.ja.20170503.12

Received: June 23, 2017; Accepted: July 26, 2017; Published: October 24, 2017

\begin{abstract}
Acute exacerbation of chronic obstructive pulmonary disease (COPD) is a common cause of intensive care unit (ICU) admission due to respiratory failure which often necessitates mechanical ventilation (MV). This study evaluated the rapid shallow breathing index (RSBI) as a predicator of ventilatory support necessity in patients admitted with acute exacerbation of COPD. This study was conducted on 100 acute COPD exacerbation patients who admitted to the critical care department at Alexandria main university hospital. All enrolled patients $(n=80)$ were subjected on admission to RSBI measurement on admission and every 30 minutes for the first 2 hours. The RSBI cutoff value that discriminated best between the need for noninvasive and invasive MV using the Receiver Operating Characteristic (ROC) was $>241 \mathrm{breath} / \mathrm{minute} / \mathrm{Liter}$, it showed a sensitivity of $88.33 \%$ and a specificity of $100 \%$. RSBI may be a good predictor of ventilatory support necessity in acute exacerbation of COPD.
\end{abstract}

Keywords: Critical, Pulmonology, Rapid Shallow Breathing Index, Ventilation

\section{Introduction}

Chronic Obstructive Pulmonary Disease (COPD) is a common disease characterized by persistent airflow limitation that is usually progressive and associated with an enhanced chronic inflammatory response in the airways and the lung to noxious particles or gases. Exacerbations and comorbidities contribute to the overall severity in individual patients. [1] COPD is a leading cause of mortality and results in an economic and social burden that is substantial and increasing [2-4]. The characteristic symptoms of COPD are chronic and progressive dyspnea, cough and sputum production. $[5,6]$

Acute COPD exacerbation is an acute event characterized by worsening of the patient's respiratory symptoms that is beyond normal day-to-day variations and leads to a change in his regular COPD medications. Management of acute exacerbation of COPD beside treating the cause includes
Supplemental oxygen, bronchodilators, corticosteroids, antibiotics and ventilatory support if needed. [7-9]

The Rapid shallow breathing index (RSBI) is defined as the ratio of respiratory frequency to tidal volume (f/VT). It is widely used in predicting the weaning of mechanical ventilation. $[10,11]$ The aim of this study was to evaluate the role of RSBI as a predicator of ventilatory support necessity in acute COPD exacerbation patients admitted to ICU.

\section{Methods}

After ethical approval for this clinical trial from the local committee of ethics in the faculty of medicine of Alexandria university and the department of critical care, Informed consent was taken from the next of kin. This prospective study was conducted on 100 adult COPD patients admitted to the critical care department with acute exacerbation between the $1^{\text {st }}$ of February 2016 and $2^{\text {nd }}$ September of 2016. 
All enrolled patients were adults of both genders. Any patients with respiratory arrest or hemodynamic instability were excluded. Also, any uncooperative patient was excluded. No pregnant females were enrolled in this study. All enrolled patients on admission were subjected to complete history taking, complete physical examination and routine laboratory investigations. During the first 2 hours of ICU admission the following parameters were monitored every 30 minutes: Vital signs, Glasgow coma score (GCS), arterial blood gases (ABG) and Rapid shallow breathing index (RSBI), a ratio determined by the respiratory rate divided by spontaneous tidal volume in liters. Acute Physiology and Chronic Health Evaluation (APACHE II) score was calculated for all patients. Then, according to mechanical ventilation (MV), patients were classified into 2 groups of requiring non-invasive $\mathrm{MV}$ (NIMV) and requiring invasive MV (IMV).

\section{Statistical Analysis}

Data were analyzed using SPSS software package version 24.0 (SPSS, Chicago, IL, USA). Quantitative data were expressed using range, mean, standard deviation and median while Qualitative data were expressed in frequency and percent. Qualitative data were analyzed using Chi-square test also exact tests such as Fisher exact was applied to compare the two groups. Normally distributed quantitative data were analyzed using student t-test while quantitative data that were not normally distributed was analyzed using Mann Whitney test for comparing the two groups. In addition, ROC was used to determine sensitivity of different variables in predicting mechanical ventilation requirement. $p$ value equal or less than 0.05 was considered significant.

\section{Results}

Regarding demographic data, there was no difference in sex of both studied groups. NIMV group showed 15 females $(25 \%)$ and 45 males (75\%), while IMV group showed 13 females $(32.5 \%)$ and 27 males $(67.5 \%)$. The age of NIMV group ranged from 41-72 years with a mean of $52.30 \pm 7.88$ years, and 45-87 years with a mean of $61.93 \pm 9.59$ years in IMV group, showing a significant difference between the 2 groups $(p=0.004)$.

Regarding the symptoms of acute COPD exacerbation, there was no significant difference between the 2 groups. 46 patients $(76.66 \%)$ of NIMV group suffered from the 4 cardinal symptoms and only 14 patients (23.3\%) didn't experience the increase in the purulence of their sputum, but in IMV group, 32 patients (80\%) suffered from the 4 cardinal symptoms but only 8 patients $(20 \%)$ didn't experience any increase in the purulence of their sputum. There was no significant difference between the two groups as regards symptoms of exacerbation of COPD. Regarding the precipitating factors of acute exacerbation, most patients in both groups were presented with chest infection and there were no any significant differences between them. The mean APACHE II score showed a statistically significant difference between the 2 groups in favor of IMV group. $(p<0.001)$ (Table 1).

Table 1. Demographic data of The two studied groups.

\begin{tabular}{|c|c|c|c|c|}
\hline & $\operatorname{NIMV}(n=60)$ & IMV $(n=40)$ & test & p value \\
\hline \multicolumn{5}{|l|}{ Age } \\
\hline Min. - Max. & $41-72$ & $45-87$ & \multirow{3}{*}{$\mathrm{t}=1.417$} & \multirow{3}{*}{$0.004^{*}$} \\
\hline Mean \pm SD & $52.30 \pm 7.88$ & $61.93 \pm 9.59$ & & \\
\hline Median & 54 & 60 & & \\
\hline \multicolumn{5}{|l|}{ Sex } \\
\hline $\begin{array}{l}\text { Male } \\
\text { Female }\end{array}$ & $\begin{array}{l}45(75 \%) \\
15(25 \%)\end{array}$ & $\begin{array}{l}27(67.5 \%) \\
13(32.5 \%)\end{array}$ & \multirow[t]{2}{*}{$\chi^{2}=0.082$} & $\mathrm{pFE}=0.5$ \\
\hline \multicolumn{4}{|c|}{ APACHE II score } & \\
\hline Min. - Max. & $7.0-20.0$ & $18.0-39.0$ & \multirow{3}{*}{$\mathrm{t}=1.583$} & \multirow{3}{*}{$<0.001^{*}$} \\
\hline Mean \pm SD & $11.68 \pm 2.47$ & $25.03 \pm 4.35$ & & \\
\hline Median & 11.0 & 25.0 & & \\
\hline
\end{tabular}

$\mathrm{t}, p$ values of Student t-test for comparing between the 2 groups.

FE: Fisher Exact for Chi square test for comparing between the two groups

*: Statistically significant at $p \leq 0.05$

Regarding the measured vital signs in the 5 stages (on admission and every 30 minutes for the first 2 hours), heart rate on admission and respiratory rate in each stage were significantly higher in IMV group. When comparing respiratory rate values at $30,60,90$ and 120 minutes with respiratory rate on admission, they showed a statistically significant difference in both groups $(p=0.001)$ and when comparing the repeated measures of heart rate with admission, only values at 90 and 120 minutes showed a statistically significant difference in NIMV group $(p<0.05)$, and values at 60,90 and 120 minutes showed a statistically significant difference in IMV group $(p<0.05)$. GCS assessment in the 5 stages showed that, it was significantly higher in NIMV group $(p=0.001)$. When comparing GCS at $30,60,90$ and 120 minutes with GCS on admission, it showed a statistically significant difference in both groups $(p=0.001)$.

Regarding the routine laboratory investigations, there were no any significant differences between the 2 groups in terms of hematocrit, white blood count, electrolytes, serum creatinine, blood urea nitrogen, $\mathrm{C}$ reactive protein or Ddimer. There was only a statistically significant difference between the 2 groups regarding platelets count in favor of NIMV group $(p<0.05)$. Regarding admission ABG, the mean 
pH was $7.28 \pm 0.02$ in NIMV, while it was $7.16 \pm 0.09$ in IMV (Figure 1). Findings of ABG in NIMV patients were considerably better than IMV group. There was only a significant difference between the two groups regarding $\mathrm{pH}$

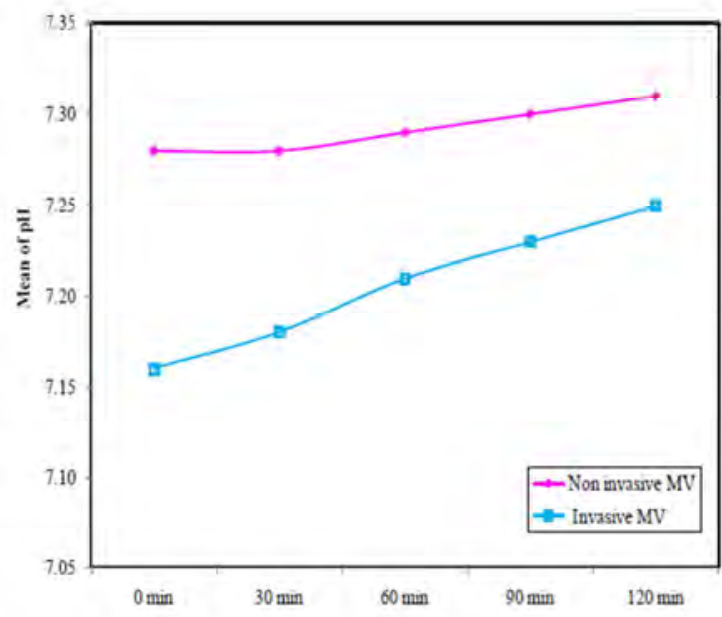

and arterial carbon dioxide tension $\left(\mathrm{PaCO}_{2}\right)(p<0.05)$. When comparing $\mathrm{pH}$ and $\mathrm{PaCO}_{2}$ values at 30, 60, 90 and 120 minutes with $\mathrm{pH}$ and $\mathrm{PaCO}_{2}$ on admission, they showed a statistically significant difference in both groups $(p<0.05)$.

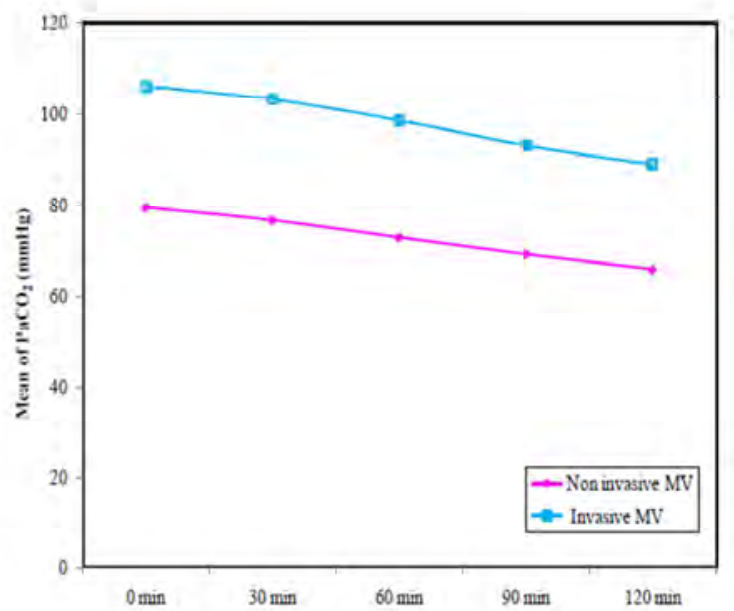

Figure 1. Main Arterial Blood Gases parameters between the 2 studied groups.

Regarding tidal volume and minute volume measured in the 5 stages, results showed a statistically significant difference between the 2 groups, it was worse in IMV group $(p<0.05)$ (Table 2).

Table 2. Comparison between the two studied groups according to tidal volume.

\begin{tabular}{|c|c|c|c|c|c|}
\hline Tidal Volume (liter) & 0 min & 30 min & $60 \mathrm{~min}$ & 90 min & $120 \mathrm{~min}$ \\
\hline \multicolumn{6}{|l|}{$\operatorname{NIMV}(n=60)$} \\
\hline Min. - Max. & $0.12-0.24$ & $0.12-0.24$ & $0.12-0.26$ & $0.13-0.26$ & $0.15-0.27$ \\
\hline Mean \pm SD & $0.17 \pm 0.03$ & $0.18 \pm 0.03$ & $0.19 \pm 0.03$ & $0.20 \pm 0.03$ & $0.21 \pm 0.03$ \\
\hline$p_{1}$ value & & $<0.001^{*}$ & $<0.001^{*}$ & $<0.001^{*}$ & $<0.001^{*}$ \\
\hline \multicolumn{6}{|l|}{$\operatorname{IMV}(n=40)$} \\
\hline Min. - Max. & $0.08-0.20$ & $0.09-0.22$ & $0.09-0.22$ & $0.10-0.24$ & $0.10-0.26$ \\
\hline Median & 0.12 & 0.12 & 0.13 & 0.14 & 0.15 \\
\hline$p_{1}$ value & & $<0.001^{*}$ & $<0.001^{*}$ & $<0.001^{*}$ & $<0.001^{*}$ \\
\hline$t$ & 6.531 & 6.179 & 6.419 & 6.157 & 5.721 \\
\hline$p$ value & $<0.001^{*}$ & $<0.001^{*}$ & $<0.001^{*}$ & $<0.001^{*}$ & $<0.001^{*}$ \\
\hline
\end{tabular}

$\mathrm{t}, p$ values for Student t-test for comparison between the 2 groups.

$p_{1}$ : Stands for (adjusted Bonferroni) p-value for ANOVA with repeated measures for comparison between 0 min with each other period

*: Statistically significant at $p \leq 0.05$

Table 3. Comparison between 2 studied groups according to rapid shallow breathing index.

\begin{tabular}{|c|c|c|c|c|c|}
\hline RSBI (Breath/minute/Liter) & $0 \mathrm{~min}$ & $30 \mathrm{~min}$ & $60 \mathrm{~min}$ & $90 \mathrm{~min}$ & $120 \mathrm{~min}$ \\
\hline \multicolumn{6}{|l|}{$\operatorname{NIMV}(n=60)$} \\
\hline Min. - Max. & $130.0-241.0$ & $115.0-233.0$ & $106.0-291.0$ & $92.0-170.0$ & $88.0-151.0$ \\
\hline Mean $\pm \mathrm{SD}$ & $189.42 \pm 29.83$ & $168.86 \pm 27.90$ & $144.25 \pm 28.83$ & $125.06 \pm 17.16$ & $115.16 \pm 13.39$ \\
\hline Median & 187.50 & 166.0 & 141.50 & 124.0 & 109.0 \\
\hline$p_{1}$ value & & $<0.001^{*}$ & $<0.001^{*}$ & $<0.001^{*}$ & $<0.001^{*}$ \\
\hline \multicolumn{6}{|l|}{$\operatorname{IMV}(n=40)$} \\
\hline Min. - Max. & $157.0-687.0$ & $138.0-555.0$ & $130.0-500.0$ & $125.0-450.0$ & $107.0-346.0$ \\
\hline Median & 342.50 & 303.0 & 244.50 & 210.0 & 116.0 \\
\hline$p_{1}$ value & & $<0.001^{*}$ & $<0.001^{*}$ & $<0.001^{*}$ & $<0.001^{*}$ \\
\hline$t$ & $7.587^{*}$ & $6.785^{*}$ & $6.284^{*}$ & $6.583^{*}$ & $6.875^{*}$ \\
\hline$p$ value & $<0.001^{*}$ & $<0.001^{*}$ & $<0.001^{*}$ & $<0.001^{*}$ & $<0.001^{*}$ \\
\hline
\end{tabular}

$\mathrm{t}, p$ values for Student $\mathrm{t}$-test for comparison between the 2 groups.

$\mathrm{p}_{1}$ : Stands for (adjusted Bonferroni) p-value for ANOVA with repeated measures for comparison between 0 min with each other period.

*: Statistically significant at $\mathrm{p} \leq 0.05$

RSBI: rapid shallow breathing index 
Regarding the main study concept, RSBI measured in the 5 stages showed a statistically significant difference between the 2 groups $(p<0.001)$. RSBI was higher in group B and when comparing RSBI values at 30, 60, 90 and 120 minutes with RSBI on admission, they showed a statistically significant difference in both groups $(p<0.001)$ (Table 3$)$. The RSBI cutoff value that discriminated best between the need for NIMV and the need for IMV was > 241 breath/minute/Liter that showed a sensitivity of $88.33 \%$ and a specificity of $100 \%$ for determining the need for IMV with $100 \%$ positive predictive value (PPV) and $90.9 \%$ negative predictive value (NPV) (Figure 2).

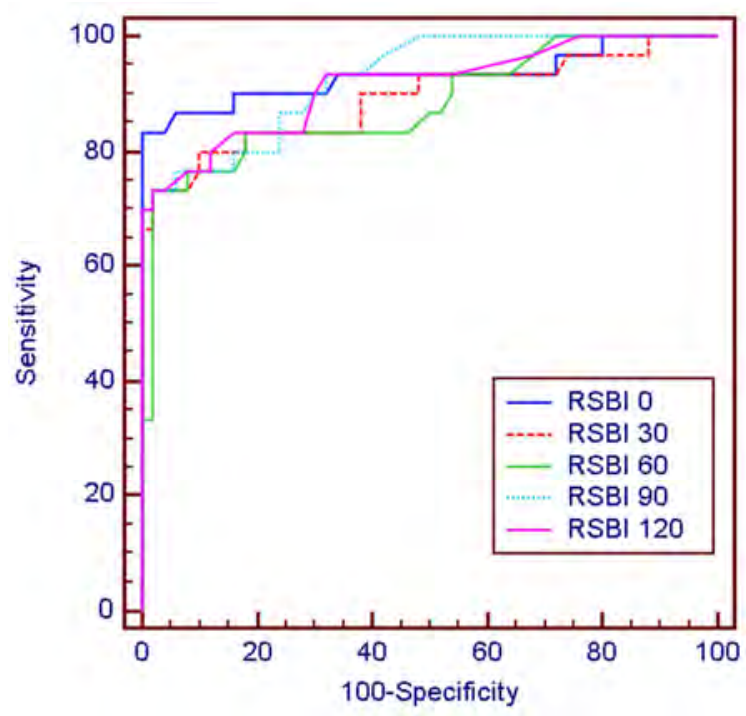

Figure 2. ROC curve for Rapid Shallow Breathing Index.

\section{Discussion}

Evidence justifying the role of RSBI in mechanically ventilated patients is yet to be fully demonstrated, although RSBI has been tested in many situations such as weaning of mechanically ventilated patients, post cardiac surgery patients and acute respiratory failure. In addition, it was compared with many predictive indices. To determine the indications of mechanical ventilation, different criteria have been stated most of them necessitate $A B G$ analysis for definite indication of mechanical ventilation requirement. [11] Very few studies has been carried out to eliminate invasive interventions for determining ventilatory needs including Crawford's study [12] in which different parameters have been studied such as: RSBI, pH, Lactate, minute volume, Carbon Dioxide production, End-Tidal $\mathrm{CO}_{2}$ and APACHE II score.

In this study using the Receiver Operating Characteristic (ROC), the RSBI on admission evaluated sensitivity ratio was $83.33 \%$ and specificity value was $100 \%$. In the subsequent 4 stages, the evaluated sensitivity ratios were $73.33 \%$ and specificity values were $98 \%$. Cut off points in the 5 stages were more than 241, 223, 188, 164 and 147, respectively were associated with high sensitivity and specificity for determining the need for IMV. RSBI $>241$ was associated with the highest sensitivity and specificity for determining the need for IMV. RSBI $\leq 241$, 223, 188, 164 and 147, respectively were associated with high sensitivity and specificity for determining the need for NIMV. RSBI $\leq 241$ was associated with the highest sensitivity and specificity for determining the need for NIMV.

In accordance with this study as regarding the predictive ability of RSBI for necessity of MV, Hassan Soleimanpour et al. [15] tested the hypothesis that RSBI could predict necessity of NIMV in COPD exacerbation. Hassan's study was conducted on 98 patients divided into 2 groups of requiring NIMV and not requiring NIMV. Logistic Regression statistical tests revealed that RSBI prior to treatment, an hour and 2 hours subsequent to treatment, in addition to possessing high diagnostic sensitivity in patients requiring NIMV, has also a significant predictive ability on admission in patients requiring NIMV. As at each measured stage, evaluated sensitivity ratios were $94.8 \%, 92.8 \%, 97.7 \%$ and specificity values were $94.8 \%, 92.8 \%$ and $97.7 \%$, respectively and values for cutoff point were $\geq 110,105$ and 107, respectively. Also, Crawford et al. [14] conducted a blinded observational trial. The threshold value for RSBI that discriminated best between no NIMV and the need for NIMV was determined in 61 patients. 35 patients who did not require NIMV had a mean RSBI of 105, and 26 patients with NIMV had a mean RSBI of 222. A ROC curve was constructed, a RSBI $>120$ showed a sensitivity of $81 \%$ and a specificity of $74 \%$.

In this study, the mean APACHE II score in IMV group was higher than in NIMV group $(p<0.001)$. The Putinati study [16] was conducted on a group of 59 patients with COPD admitted with acute respiratory failure and a high APACHE II score. High APACHE II score was predictive of failure of NIMV and the need for intubation, a result in accordance with Confalonieri et al. [17] and Lin et al. [18]. However, in the study of Lin [18], RSBI failed to be considered as good predicting factor of successful NIMV intervention in patients with acute respiratory failure. Youshida et al. [19], observed that patients in need of intubation had significantly higher APACHE II scores and lower arterial $\mathrm{pH}$, as APACHE II score higher than 17 and respiratory rate above 25 breaths/minute after receiving NIMV for 1 hour were introduced as independent determinants of requiring intubation.

In this study, there was a significant difference in admission level of acidosis and hypercapnia between patients enrolled in the study and also a significant difference was noted after initiation of MV either with NIMV or IMV. In Putinati et al. study [16], they found a significant difference in admission level of acidosis and hypercapnia between patients successfully ventilated with NIMV and those who failed with NIMV. NIMV was effective in reducing $\mathrm{PaCO}_{2}$ levels and improving $\mathrm{pH}$ in all patients, a result in accordance with the findings of Brochard, Meduri, 
Ambrosino and Wysocki. [20-23]

\section{Conclusion}

The Rapid Shallow Breathing Index cutoff value that discriminated best between the need for noninvasive and invasive MV using the Receiver Operating Characteristic (ROC) was $>241$ breath/minute/Liter, it showed a sensitivity of $88.33 \%$ and a specificity of $100 \%$. RSBI may be a good predictor of ventilatory support necessity in acute exacerbation of COPD. The limitation of this study was the small sample size. Further studies are recommended the evaluate the use of serial RSBI and RSBI rate together.

\section{References}

[1] Global strategy for the diagnosis, management, and prevention of chronic obstructive pulmonary disease: Executive summary 2015. Global Initiative for Chronic Obstructive Lung Disease [GOLD]. Available at: www.goldcopd.org.

[2] Lopez AD, Shibuya K, Rao C, Mathers CD, Hansell Al, Held LS, et al. Chronic obstructive pulmonary disease: current burden and future projections. Eur Respir J 2006; 27 [2]: 397 412 .

[3] Mathers CD, Loncar D. Projections of global mortality and burden of disease from 2002 to 2030. Po LS Med 2006; 3: e442.

[4] Salvi SS, Barnes PJ. Chronic obstructive pulmonary disease in non-smoker. Lancet 2009; 374: 733-43.

[5] Kessler R, Partridge MR, Miravitlles M, Cazzola, M, Vogelmeier, C, Leynaud, D, Ostinelle, J. Symptoms variability in patients with severe COPD: a pan-European cross-sectional study. Eur Respir J 2011; 37: 264-72.

[6] Espinosa de los Monteros MJ, Pena C, Soto Hurtado EJ, Jareno J, Miravitlles M. Variability of respiratory symptoms in severe COPD. Arch Bronconeumol 2012; 48: 3-7.

[7] Rodriguez-Roisin R. Toward a consensus definition for COPD exacerbations. Chest 2000; 117: 398S-401S.

[8] Burge S, Wedzicha JA. COPD exacerbation: definitions and classifications. Eur Respir J Suppl 2003; 41: 46s-53s.

[9] Celli BR, Barnes PJ, Exacerbations of chronic obstructive pulmonary disease. Eur Respir J 2007; 29: 1224-38.

[10] Boutou AK, Abatzidou F, Tryfon S, Nakou C, Pitsiou G, Argyropoulou P, et al. Diagnostic accuracy of the rapid shallow breathing index to predict a successful spontaneous breathing trial outcome in mechanically ventilated patients with chronic obstructive pulmonary disease. Heart Lung. 2011; 40: 105-10.
[11] Purro A, Appendini L, De Gaetano A, Gudjonsdottir M, Donner CF, Rossi A. Physiologic determinants of ventilator dependence in long-term mechanically ventilated patients. Am J Respir Crit Care Med. 2000; 161 (4 Pt 1): 1115-23. [PubMed].

[12] Puri BK. SPSS in Practice, an Illustrated Guide: Arnold, London, 2002; pp 320.

[13] Antro C, Merico F, Urbino R, Gai V. Non-invasive ventilation as a first-line treatment for acute respiratory failure: "real life" experience in the emergency department. Emerg Med J. 2005; 22 [11]: 772-7.

[14] Crawford J, Otero R, Donnino M, Garcia J, Khazal R, Lenoir T. Rapid shallow breathing index - a key predictor for noninvasive ventilation. J Crit Care. 2007; 11 [Suppl 2]: 169.

[15] Hassan Soleimanpour, Ali Taghizadieh, Rasoul Salimi, Samad EJ Golzari, Ata Mahmoodpoor, Saeid Safari et al. Rapid shallow breathing index survey, a predictor of non-invasive ventilation necessity in patients with chronic obstructive pulmonary disease exacerbation: an analytical descriptive prospective study. Iran Red Crescent Med J. 2014; 16 [2]: e13326.

[16] Putinati S, Ballerin L, Piattella M, Panella GL, Potena A. Is it possible to predict the success of non-invasive positive pressure ventilation in acute respiratory failure due to COPD? Respir Med 2000; 94 [10]: 997-1001.

[17] Confalonieri M, Aiolfi S, Gandola L, Scartabellati A, Della Porta R, Parigi P. Severe exacerbations of chronic obstructive pulmonary disease treated with $\mathrm{Bi}$ PAP by nasal mask. Respiration 1994; 61: 310 \pm 316 .

[18] Lin MS, Guo HR, Huang MH, Chen CR, Wu CL. Predictors of successful noninvasive ventilation treatment for patients suffering acute respiratory failure. J Chin Med Assoc 2008; 71 [8]: 392-398.

[19] Yoshida Y, Takeda S, Akada S, Hongo T, Tanaka K, Sakamoto A. Factors predicting successful noninvasive ventilation in acute lung injury. J Anesth. 2008; 22 [3]: 201-6.

[20] Brochard L, Mancebo J, Wysocki M, et al. Noninvasive ventilation for acute exacerbations of chronic obstructive pulmonary disease. N Engl J Med 1995; 333: 817 \pm 822 .

[21] Meduri GU, Abou-Shala N, Fox RC, Jones CB, Leeper KV, Wunderink RG. Noninvasive face mask mechanical ventilation in patients with acute hypercapnic respiratory failure. Chest 1991; 100: 445 \pm 454 .

[22] Brochard L, Isabey D, Piquet J, et al. Reversal of acute exacerbations of chronic obstructive lung disease by inspiratory assistance with a face mask. N Engl J Med 1990; 323: $1523-30$.

[23] Fernandez R, Blanch LP, Valles J, Baigorri F, Artigas A. Pressure support ventilation via face mask in acute respiratory failure in hypercapnic COPD patients. Intensive Care Med 1993; 19: 456-61. 